\title{
Deception in Social Psychological Experiments: Two Misconceptions and a Research Agenda*
}

\author{
RALPH HERTUIG \\ University of Basel, Basel \\ ANDREAS ORTMANN \\ Charles University and Academy of Sciences of the Czech Republic, Prague
}

l Constructing the Subject, Kurt Danziger (1990) traces the history of psychology's research methodology from the nineteenth century to the emergence of modern rules of experimentation; the changes are striking. In today's psychology laboratories, there is a strict division of labor. One is either an experimenter or a participant, but never both-at least, not in the same laboratory. Not so in Wilhelm Wundt's laboratory at the University of Leipzig, the dedication of which in 1879 is generally recognized as the birth of modern experimental psychology. In Wundt's laboratory, the roles of participant and experimenter were fluid, and laboratory members took on both roles. Wundt himself participated regularly as a subject in the experiments published by his students; he also contributed much of the underlying theory. That this giant himself served as a data source and rarely, if ever, as an experimenter suggests that the role of subject was thought to require greater psychological sophistication than that of experimenter.

Retracing the history of one's discipline helps demonstrate that its practices of experimentation are also a product of its times, notwithstanding often deeply entrenched beliefs to the contrary. Deception of participants is an experimental tool about which many currently harbor strong beliefs; some, for instance, deem it indispensable (e.g., Bröder 1998; Kimmel 1998). In Wundt's laboratory, deception was impossible. Researchers at the Leipzig laboratory would

\footnotetext{
* Send correspondence to: Ralph Hertwig, University of Basel, Department of Psychology, Missionsstrasse 60/62, 4055 Basel, Switzerland, Tel.: (+41 61) 2670611 , E-mail: ralph.hertwig@unibas.ch.
}

function as participants, experimenters, and theorists for one another. Deception would have meant self-deception or deception of close collaborators. One does not have to travel in time, however, to realize that a discipline's preferred practices of experimentation are relative. Sometimes glancing beyond the fence of one's discipline suffices. In laboratories of experimental economists, the use of deception is essentially impossible because the community has effectively proscribed it (although there are rare exceptions). Economists fear that participants' expectations of being deceived trigger suspitcionband second-guessing, and that these responses swamp the impact of the experimental scenario on behavior (see Hertwig and Ortmann 2001, 2003; Ortmann and Hertwig 2002).

Having established that beliefs about the rules of experimentation evolve and differ across disciplines, we discuss two widespread misconceptions about the contemporary use of deception in psychology and sketch a research agenda for the future. Before we do so, however, let us briefly clarify what is typically considered to be deception. Although deception is not easily defined, a consensus has emerged across disciplinary borders that intentional and explicit provision of erroneous information-in other words, lying-is deception, whereas withholding information about research hypotheses, the range of experimental manipulations, or the like ought not to count as deception. In the words of the economist Hey (1998:397), "there is a world of difference between not telling subjects things and telling them the wrong things. The latter is deception, the former is not" 
(his emphasis). ${ }^{1}$ Economists' proscription of deception targets the explicit and intentional provision of erroneous information.

\section{MISCONCEPTION ONE: DECEPTION AS A LAST RESORT}

Both the American Psychological Association (APA) and the American Sociological Association (ASA) define parameters for the use of deception very tightly. According to the APA rules of conduct (2002: Standard 8.07):

Psychologists do not conduct a study involving deception unless they have determined that the use of deceptive techniques is justified by the study's significant prospective scientific, educational, or applied value and that effective nondeceptive alternative procedures are not feasible.

The purport of the ASA Code of Ethics on the use of deception in research is nearly identical (1999: Standard 12.05):

Sociologists do not use deceptive techniques (1) unless they have determined that their use will not be harmful to research participants, is justified by the study's prospective scientificied educat tional, or applied value; and that equally effective alternative procedures that do not use deception are not feasible.

In order to evaluate the degree to which these rules succeed in ruling our conduct, let us spell out what we believe is their objective: the default is that researchers do not use deception. Yet, if they end up using it, then several important conditions will need to be met (no harm, prospective value, no effective

\footnotetext{
${ }^{1}$ No common ground has (yet) been established with respect to the violation of participants' default assumptions. One likely default assumption is that the experiment starts only after an experimenter has clearly indicated its beginning, and therefore that a participant's initial interactions with the experimenter (upon entering the laboratory) are not an object of investigation. Whether or not violations of default assumption ought to count as deception is of particular relevance in the use of those "covert methods" in field research that represent omission of information (as opposed to lies). For instance, it seems safe to assume that employees at a restaurant do not expect a co-worker to secretly record their conversations (for discussions of covert methods in field research and their ethical implications see Fine, 1993; Erikson, 1995, 1996; Herrera, 1999; Leo, 1995, 1996).
}

alternatives). In light of these conditions, it seem reasonable to conclude that deception is meant to be used as a last-resort method, and some even see it confined to the rarest of cases (e.g., "Committee on the Use of Human Research Subjects" of Purdue University). But is deception really used by necessity?

One way of answering the question of whether deception is used as a last-resort method is simply to look at the numbers. Hertwig and Ortmann (2008) analyzed the frequency of deception in the Journal of Experimental Social Psychology (JESP) in 2002. In that year, JESP published 27 articles and 32 reports encompassing a total of 117 studies. Of these, 63 (53\%) used deception. The most recent estimate available for the Journal of Personality and Social Psychology (JPSP) is, to the best of our knowledge, that of Epley and Huff (1998). For 1996, they found that $42 \%$ of articles in JPSP reported studies involving deception. Although the use of deception in social psychology experiments has dropped, compared with its heyday in the 1960s and 1970s (see Hertwig and Ortmann 2.008), the frequency of deception in contemporary:social psychology is still substantial, and in marketing research, for instance, it even appears to have risen from $43 \%$ in $1975-76$ to 56\% in 1996-97 (Kimmel 2001). To the best of our knowledge, analyses quantifying the frequency of deceptive methods in ethnographic field research have not been conducted.

It is difficult to reconcile the still relatively high prevalence of its use with the notion that deception is reserved for those cases in which the study's prospective value justifies its use and effective alternatives are not feasible. Indeed, it is easy to find deception studies in which the latter criterion is not met. One just has to browse through those studies investigating social games, such as those involving ultimatum and trust (see Eckel 2007). A look at these studies is particularly informative because of the many economic studies using such games without deception. In psychology, one can find studies in which players are misled to believe that their allocation decisions will determine their final payoffs, that assignment of roles is determined by chance, that 
there is a real other person with whom they are paired up. These deceits are typically driven by convenience rather than necessity.

Psychology's ethical guidelines for research have become substantially stricter (see Rosnow and Rosenthal 1997). Consequently, the profession has succeeded in reducing the severity of deceptive methods, and many of the well-known studies that raised daunting ethical issues would be impossible today (but see Burger 2007:17 on a "humane and ethical" replication of the Milgram study). Yet, deception studies are not rare. Why? One possible reason is that the APA rule suffers from a serious design flaw. It leaves the decision of whether or not deception is justified by its anticipated value to those who stand to benefit from its use (Ortmann and Hertwig 1997, 1998). Notwithstanding the mediating role of Institutional Review Boards (IRBs), this practice leaves the assessment of private benefits (e.g., deception is often less time-consuming and expensive than alternative procedures) ${ }^{2}$ and public costs (e.g., possible depletion of participants' trust) to the interested party (the experimenter). In economists' language, this represents a classic moral-hazard problem whose solution is likely to sacrifice the public interest.

\section{MISCONCEPTION TWO: THE COSTS OF SUSPICIOUSNESS ARE NEGLIGIBLE}

Over the years, a number of psychologists have expressed the same concern that led experimental economists to forego the use of deception (e.g., Kelman 1967; Ring 1967; for others, see Table 13.2 in Hertwig and Ortmann 2003). Elsewhere, we reiterated the concern that the use of deception may destroy participants' trust, trigger suspicion and secondguessing, and ultimately endanger experimental control (Ortmann and Hertwig 1997, 1998). In response, Kimmel (1998:804) argued: "By the early 1970s, investigators

\footnotetext{
${ }^{2}$ For instance, in the study of social games pretending that a player is being paired up with another personwhen indeed there is none-saves time and money (e.g., in terms of recruitment and payment of participants).
}

reported high rates of suspiciousness among participants in conformity studies, ranging from $50 \%$ to nearly $90 \%$. . . Nonetheless, the effects of suspiciousness on research performance, though somewhat inconsistent, appear to be negligible." It is likely to be no coincidence that Kimmel made reference to research on conformity behavior. Hertwig and Ortmann (2008) found this to be the only topic in social-psychology research in which the effect of suspiciousness has been systematically investigated in more than a couple of studies. Using the keyword "deception" in combination with "suspicion" (and various variants), we searched for studies in the PsycINFO/PsycLIT database and found fourteen studies that systematically compared the behavior of suspicious and unsuspicious participants. In ten of these studies suspicious participants showed less conformity behavior and four studies found no significant differences; no study reported greater conformity among suspicious participants. In nine of the ten studies where suspiciousness was found to attenuate conformity, the effect size was of medium to large magnitude.

2008 To conchude, there is one social-psychological research topic, social conformity, in which there is an appreciable number of studies investigating the consequences of suspiciousness; the results are clear. Those suspicious of being tricked were less likely to bend to feigned social pressure. Contrary to Kimmel (1998), the effects of suspiciousness on research performance are neither inconsistent nor negligible - at least not in conformity studies. Of course, the effect of suspiciousness may not always be so easy to discern. In research on conformity, suspiciousness suggests an obvious alternative behavior: not to give in to the feigned social pressure. In other designs, it may be much less obvious to people as to how they should act upon their suspicions. If so, suspiciousness may enhance random variation, making it harder for the experimenter to reject the null hypothesis. Or, suspiciousness may only gradually reveal itself as the common denominator behind a series of successful and failed attempts to replicate an effect (such as in research on the weapons effect; see Page and Scheidt 1971; Simons and 
Turner 1976). Or, as McKenzie, Wixted, and Noelle (2004:947) warned, suspicion may be erroneously interpreted as "irrational behavior," because the experimenter falsely supposes that participants believe key task parameters lock, stock, and barrel.

\section{A RESEARCH AGENDA SUPPORTING AN EVIDENCED-BASED POLICY ON DECEPTION}

In order to avoid misunderstandings, let us reiterate: We do not exclude the possibility that there are important research questions for which deception is truly unavoidable (and we said so explicitly in Hertwig and Ortmann 2001:400, 439). Therefore, we do not advocate either a ban of deception in psychology (Hertwig and Ortmann 2001:400-401, 438-439; Hertwig and Ortmann 2008), or the imposition of blanket sanctions as implied by Cook and Yamagishi (2008:215-220). Equally important, we do not argue that economists' experimental standards and practices constitute the gold standard of experimentation (Hertwig and Ortmann, 2001, pp 400, 442), let alone that they should be imposed on the social sciences! We do, however, believe that the comparison of practices and standards across disciplines fosters insight into the costs and benefits of one's preferred practices of experimentation. ${ }^{3}$ We also believe that the last-resort provisions of APA and ASA are good rules that should be honored. Finally, we believe that the evaluation of our methodological standards and policy should be evidencebased.

In evaluating the permissibility of deception, neither the APA, the ASA, nor experimental economists refer to considerations of absolute right or wrong (although there is a deontological flavor to the APA [rules of conduct 2002: Standard 8.07] postulate that "psychologists do not conduct a study involving deception"). Rather, their focus, like that of a consequentialist, is on costs and benefits.

\footnotetext{
3 The experience that glancing beyond the fence of one's discipline helps to reflect on the costs and benefits of one's methodological practices has in fact inspired usa psychologist (Hertwig) and an economist (Ortmann)to think together about these issues.
}

Cost-benefit analysis has led them to different conclusions regarding deception: psychologists to conditional endorsement and economists to proscription. Nevertheless, the two communities share a need for accurate data on the basis of which to evaluate the costs and benefits. Unfortunately, virtually no such data are currently available. Little is known about the extent to which participants in contemporary psychological studies harbor suspicion or feel distressed by being deceived. Little is known about the extent to which the aforementioned results in conformity studies generalize to other areas of psychological research. Little is known about whether new experimental methodologies, which range from imaging, computer simulations, and deception-substituting designs (Bardsley 2000 ) to virtual environments (see Dhami, Hertwig, and Hoffrage 2004:979-80), render deception less necessary or perhaps even unnecessary. Moreover, we know of no systematic retrospective investigations of the extent to which the promise of deception studies' significant "prospective scientific, educatibnal, or applied value" has indeed been realized, let alone of any systematic treatment of how to even make valid prospective assessments of these potential values. ${ }^{4}$ Perhaps most importantly, it is not known whether, in accordance with the APA rule, deception is truly used only as a last resort. We think not, and we suspect that the APA rule's design flaw is the reason why. If so, psychology needs to design and test alternative mechanisms that help reduce deception to the irreducible minimum envisioned without expanding the somewhat daunting role of IRBs (see Munsey 2007).

We believe that the most promising solution to this dilemma is to implement incentives for individual researchers to forego the routine tool of deception and to search for and implement alternative procedures. In Hertwig and Ortmann (2008), we proposed that such incentives could, for instance, be put in place

\footnotetext{
${ }^{4}$ We do not doubt that deception studies have yielded new and valuable insights. The issue is to understand which studies did and which did not, and how one can distinguish between them to make better prediction of the potential value of future studies.
} 
via the editorial process. Specifically, the APA could lobby the editors of the relevant journals to impose more transparent and stricter rules on the submission of studies incorporating deception. One key criterion against which editors and reviewers can judge the use of deception is past research practices. Specifically, authors could be asked to briefly characterize previous research practices regarding the topic they investigate (either in a cover sheet or in the body of the manuscript) and explain, for instance, why they cannot adopt the nondeceptive designs that others have used before. In this context, defining what constitutes necessity does not seem to be too difficult a task.

To conclude, most studies that have examined the costs of deception date to the period between the mid-1960s and the mid-1970s, the "most self-critical decade" of psychology (Silverman 1978:405). As Danziger (1990) showed so convincingly, beliefs regarding the rules of good experimentation and the indispensability of methods can change over time. In light of psychology's mostly consequentialist approach to the use of deception, we caninot afford to be content with observations collected during that brief time thirty years ago. Adopting a consequentialist's viewpoint without accurately assessing the consequences of one's actions reduces our rules of conduct to empty but convenient rhetoric.

\section{$R \in F \in R \in N C E S$}

American Psychological Association. 2002. Ethical Principles of Psychologists and Code of Conduct. Retrieved from http://www.apa. org/ethics/.

American Sociological Association. 1999. Code of Ethics and Policies and Procedures of the ASA Committee on Professional Ethics. Retrieved from http://www.asanet.org/.

Bardsley, Nicholas. 2000. "Control without Deception: Individual Behavior in Free-riding Experiments Revisited." Experimental Economics 3:215-240.

Bröder, Arndt. 1998. Deception Can Be Acceptable. American Psychologist 53:805-806.

Burger, Jerry. 2007. "Replicating Milgram." Observer 20:15-17.

Committee on the Use of Human Research Subjects, Purdue University. 2002. Retrieved from http://www.irb.purdue.edu/deception.shtml
Cook, Karen S. and Toshio Yamagishi. 2008. "A Defense of Deception on Scientific Grounds." Forthcoming. Social Psychology Quarterly 71(3):215-220.

Danziger, Kurt. 1990. Constructing the Subject: Historical Origins of Psychological Research. Cambridge, MA: Cambridge University Press.

Dhami, Mandeep K., Ralph Hertwig, and Ulrich Hoffrage. 2004. "The Role of Representative Design in an Ecological Approach to Cognition." Psychological Bulletin 130:959-988

Eckel, Catherine. 2007. "Economic Games for Social Scientists." Pp. 497-515 in Laboratory Experiments in the Social Sciences, edited by M. Webster, Jr. and J. Sell. Amsterdam, NL: Elsevier.

Epley, Nicholas and Chuck Huff. 1998. "Suspicion, Affective Response, and Educational Benefit as a Result of Deception in Psychology Research." Personality and Social Psychology Bulletin 24:759-768.

Erikson, Kai. 1995. "Commentary." American Sociologist 26:4-11.

Erikson, Kai. 1996. "A response to Richard Leo." American Sociologist 27:129-130.

Fine, Gary A. 1993. "Ten Lies of Ethnography: Moral Dilemmas in Field Research." Journal of Contemporary Ethnography 22:267-294

Herrera, Christopher. 1999. "Two Arguments for Covert Methods in Social Research." British Journal of Sociology 50:331-343.

Hertwig, Ralph and Andreas Ortmann. 2001. "Experimental Practices in Economics: A Methodological Challenge for Psychologists?" Behavioral and Brain Sciences 24:383-451.

Hertwig, Ralph and Andreas Ortmann. 2003. 'Economists' and Psychologists' Experimental Practices: How They Differ, Why They Differ, and How They Could Converge." Pp. 253-272 in The Psychology of Economic Decisions, edited by I. Brocas and J. D. Carillo. New York: Oxford University Press.

Hertwig, Ralph and Andreas Ortmann. 2008. "Deception in Experiments: Revisiting the Arguments in its Defense." Ethics and Behavior 18:59-92.

Hey, John D. 1998. "Experimental Economics and Deception. A Comment." Journal of Economic Psychology 19:397-401.

Kelman, Herbert C. 1967. "Human Use of Human Subjects: The Problem of Deception in Social Psychological Experiments." Psychological Bulletin 67:1-11.

Kimmel, Allan J. 1998. "In Defense of Deception." American Psychologist 53:803-805.

Kimmel, Allan J. 2001. "Deception in Marketing Research: Ethical, Methodological, and Disciplinary Implications. Psychology and Marketing 18:663-689. 
Leo, Richard. 1995. "Trial and Tribulations: Courts, Ethnography and the Need for Evidentiary Privilege for Academic Researchers." American Sociologist 26:113-134.

Leo, Richard. 1996. "The Ethics of Deceptive Research Roles Reconsidered: A Response to Kai Erikson." American Sociologist 27:122-128.

McKenzie, Craig R. M., John T. Wixted, and David C. Noelle. 2004. "Explaining Purportedly Irrational Behavior by Modeling Skepticism in Task Parameters: An Example Examining Confidence in Forced-Choice Tasks." Journal of Experimental Psychology: Learning, Memory, and Cognition 30:947-959.

Munsey, Christopher. 2007. "Fixing the Institutional Review Board System.” Monitor on Psychology 38:50.

Ortmann, Andreas and Ralph Hertwig. 1997. "Is Deception Acceptable?" American Psychologist 52:746-747.

Ortmann, Andreas and Ralph Hertwig. 1998. "The Question Remains: Is Deception Acceptable?" American Psychologist 53:806-807.
Ortmann, Andreas and Ralph Hertwig. 2002. "The Empirical Costs of Deception: Evidence From Psychology." Experimental Economics 5:111-131.

Page, Monte M. and Rick H. Scheidt. 1971. "The Elusive Weapons Effect: Demand Awareness, Evaluation Apprehension, and Slightly Sophisticated Subjects." Journal of Personality and Social Psychology 20:304-318.

Ring, Kenneth. 1967. "Experimental Social Psychology: Some Sober Questions About Some Frivolous Values." Journal of Experimental Social Psychology 3:113-123.

Rosnow, Ralph L. and Robert Rosenthal. 1997. People Studying People: Artifacts and Ethics in Behavioral Research. New York: Freeman.

Silverman, Irwin. 1978. "Expectancy effects revisited.” Behavioral and Brain Sciences 1:404-405.

Simons, Lynn Stanley and Charles W. Turner. 1976. "Evaluation Apprehension, Hypothesis Awareness, and the Weapons Effect." Aggressive Behavior 2:77-87.

Ralph Hertwig is a professor of Cognitive and Decision Sciences in the department of psychology at the University of Basel, Switzerland. His research focuses on models of bounded rationality, social intelligence, and methodology of the social sciences.enta to

University of Basel

Andreas Ortmann is a professor and seniov researcher as CERGE-EI, a joint workplace of Charles University and the Academy of Sciences of the Czech Republic, Prague. An economist by training, his research is mostly concerned with problems of asymmetric information. More detailed information is accessible at home.cerge-ei.cz/ortmann 